\title{
Octa(3-chloroammoniumpropyl) Octasilsesquioxane
}

\author{
M.-C. Gravel, C. Zhang, M. Dinderman and R. M. Laine*
}

Department of Materials Science and Engineering, University of Michigan, Ann Arbor, MI 48109-2136, USA

The octahydrochloride salt of octa(3-aminopropyl)octasilsesquioxane can be isolated in $30 \%$ yields by controlled hydrolytic condensation of 3-aminopropyltriethoxysilane in strongly acidic methanol. The analytically pure product can be filtered from the reaction solution. The product was characterized by standard analytical and spectroscopic tools. Efforts were made to explore the potential utility of the product for preparing amide and imide compounds that serve as models of polyimides with the goal of making novel materials, especially those that offer high strength and that are flame-resistant. Efforts to make the octa-acetamide were unsuccessful as the hexadeca-acetamide was formed in preference. These results provided the motivation to explore the synthesis of the succinic-anhydridederived octa-imide. This reaction was found to proceed quite readily. The latter compound is stable in nitrogen to $\approx 500{ }^{\circ} \mathrm{C}$ and more importantly, it appears to behave as a liquidcrystalline material in the temperature range 90-190 ${ }^{\circ} \mathrm{C}$. This behavior is unusual, given that no aromatic or mesogenic groups are present on the cube. Copyright (C) 1999 John Wiley \& Sons, Ltd.

Keywords: silsesquioxone; aminopropyl; polyimides; materials flame resistance; liquid crystal

Received 31 October 1998; accepted 2 December 1998

\footnotetext{
* Correspondence to: R. M. Laine, Department of Chemistry and Department of Materials Science and Engineering, University of Michigan, Ann Arbor, MI 48109-2136, USA.

Contract/grant sponsor: National Institute of Dental Research; Contract/grant number: DE09839-03.

Contract/grant sponsor: Federal Aviation Administration; Contract/ grant number: 95-G-026.
}

\section{INTRODUCTION}

Inorganic-organic hybrid materials are expected to combine the hardness and abrasion resistance of an inorganic phase with the compliance and formability of an organic phase, to produce materials that are more than simply the sum of the component parts. To do this effectively in a predictable, repeatable and tailorable manner, it is necessary to design components that can be combined at the smallest length scales possible, e.g. the atomic or molecular (nano) scales. Cubic silsesquioxanes offer considerable potential for producing hybrid materials because the cube itself is the smallest particle of sand (reinforcing inorganic phase) that can be formed, yet the vertices of these cubes can be 'decorated' with organic moieties to provide mechanisms for linking these 'sand particles' to and within an organic matrix. ${ }^{1-6}$

Because of this potential, extensive efforts have been made to develop synthetic routes to: (1) partially oligomerized ' $\mathrm{T}$ '-type silsesquioxanes as represented by the products of Scheme 1; (2) octahedral ' $T$ '-type silsesquioxanes as illustrated by the products of Scheme 2, and (3) octahedral 'DQ'-or 'spacer'-type silsesquioxanes as produced via Schemes 3-5. ${ }^{6}$

The general objectives that guide the research presented here are twofold. One is to develop lowcost routes to polyfunctional octahedral silsesquioxanes (cubes) and the second is to use these 'macromonomers' to process hybrid nanocomposites that offer potential as structural materials for dental, aerospatial, electronic (etc.) applications.

We have previously prepared methacrylate, epoxide and liquid-crystalline functionalized cubes. $^{6-9}$ In an effort to expand the types of functionality available, we sought to prepare the octa(aminopropyl) cube as a potential hybrid macromonomer. The synthesis of this cube was first described in a Wacker Chemie patent, ${ }^{10}$ then by Roziers and co-workers. ${ }^{11,12}$ However, the octa(aminopropyl) product claimed in these two 


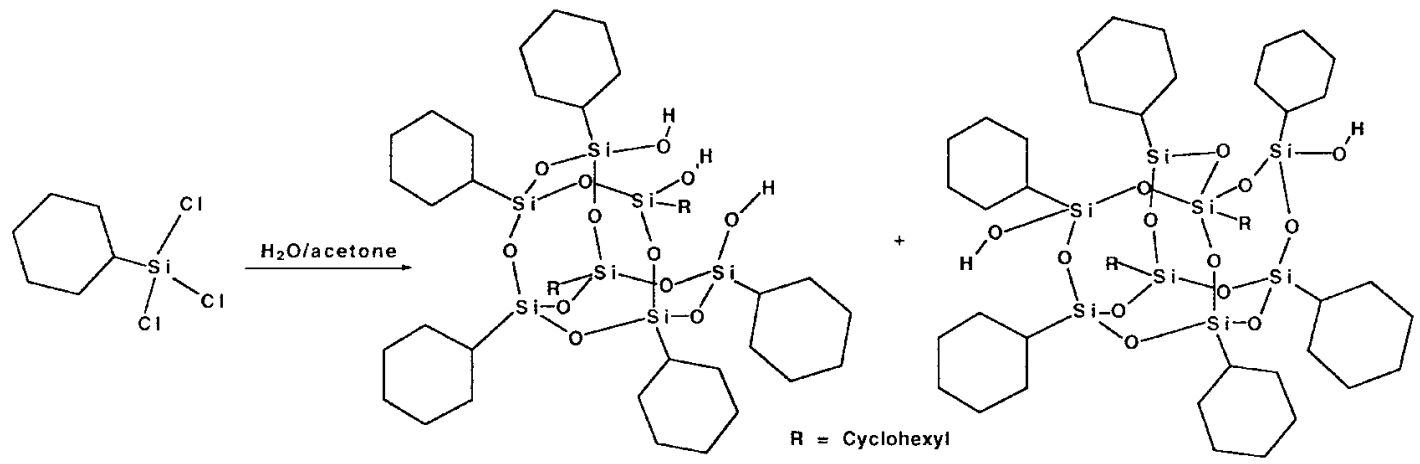

Scheme 1

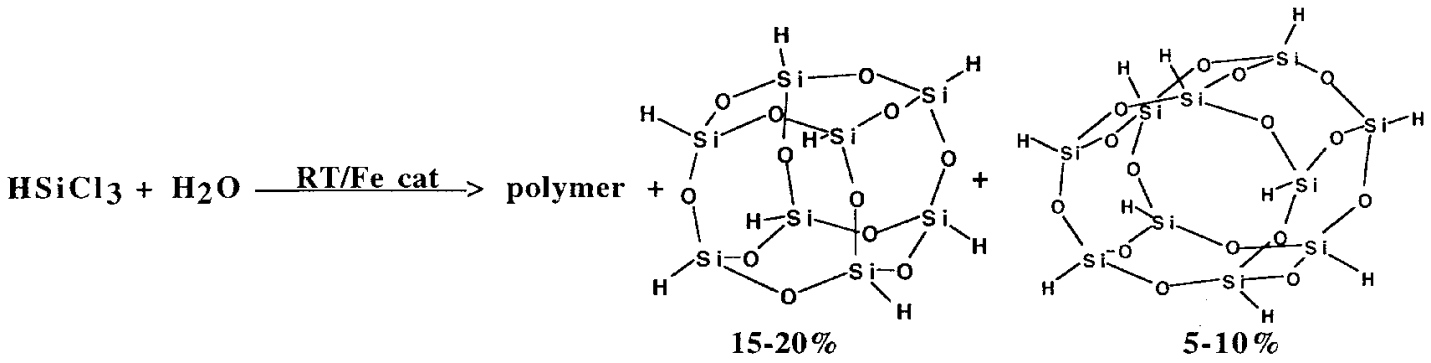

Scheme 2

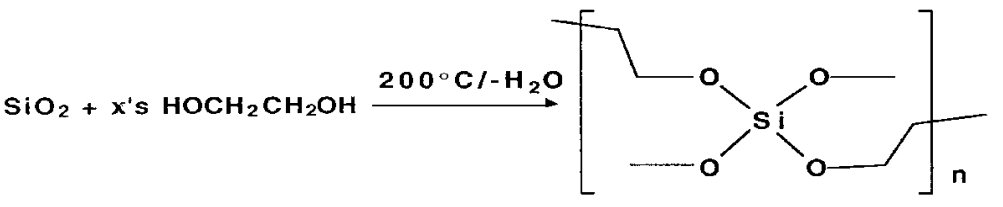

Scheme 3

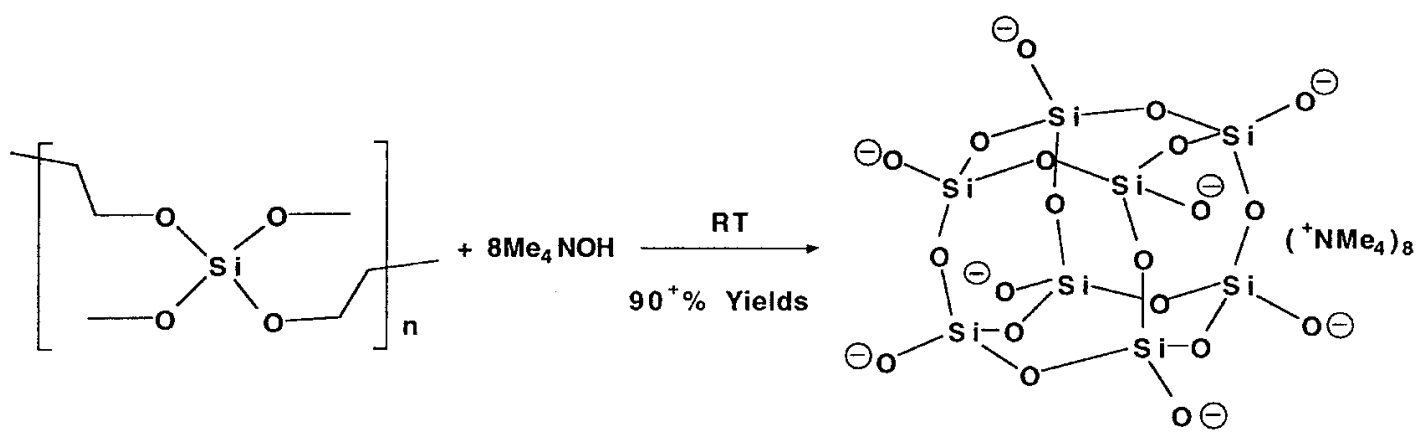

Scheme 4 


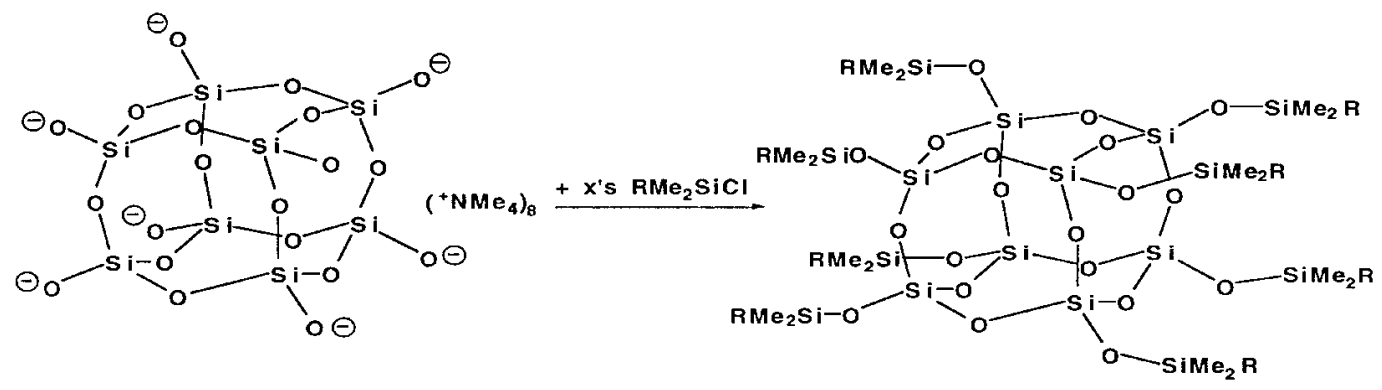

Scheme 5

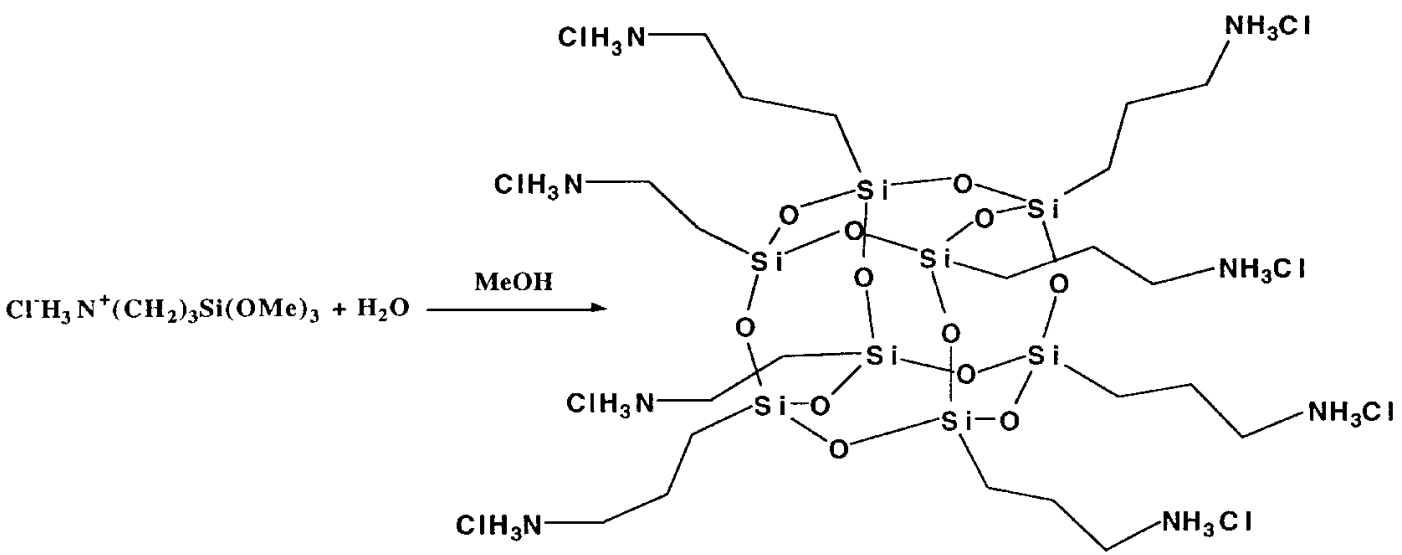

Scheme 6

reports was not actually isolated; indeed, Petridis and co-workers note that amino-functionalized silsesquioxanes cannot be isolated. ${ }^{13}$

Despite these reports, we recently described the synthesis and isolation of octa(aminopropyl) octasilsesquioxane hydrochloride salt (OCAPS) via Scheme 6 , simply by hydrolysis of aminopropyltriethoxysilane in aqueous acidic methanol. ${ }^{14}$ These results were confirmed in a brief report by Feher and Wyndham. ${ }^{15}$ In this paper, we provide more details about the OCAPS synthesis and characterization. We also present preliminary evidence that suggests the potential utility of OCAPS for synthesizing polyamide and polyimide hybrid materials.

\section{EXPERIMENTAL}

\section{Analytical methods}

\section{NMR analyses}

All NMR spectra were obtained in $\mathrm{CDCl}_{3}$ with ${ }^{1} \mathrm{H}$ and ${ }^{13} \mathrm{C}$ NMR recorded on a Varian INOVA $400 \mathrm{~Hz}$ spectrometer. ${ }^{1} \mathrm{H}$ NMR spectra obtained at $400 \mathrm{MHz}$ were collected using a $6000 \mathrm{~Hz}$ spectral width, a relaxation delay of $3.5 \mathrm{~s}$, a pulse width of $38^{\circ}$ and $30 \mathrm{~K}$ data points. ${ }^{13} \mathrm{C}\left\{{ }^{1} \mathrm{H}\right\}$ NMR spectra were obtained at $100.6 \mathrm{MHz}$ using a $25000 \mathrm{~Hz}$ spectral width, a relaxation delay of $1.5 \mathrm{~s}$, a pulse width of $40^{\circ}$ and $75 \mathrm{~K}$ data points. $\mathrm{CHCl}_{3}$ was used as internal reference for ${ }^{1} \mathrm{H}$ NMR (7.259 ppm) and $\mathrm{CDCl}_{3}$ for ${ }^{13} \mathrm{C}$ NMR (77.23 ppm). ${ }^{29} \mathrm{Si}$ NMR spectra were recorded on a Bruker AM $360 \mathrm{~Hz}$ spectrometer operating at $71.5 \mathrm{MHz}$ using a 32 $000 \mathrm{~Hz}$ spectral width, a pulse width of $90^{\circ}$, a relaxation delay of $10.0 \mathrm{~s}, 32 \mathrm{~K}$ data points tetramethylsilane and (TMS) as external reference.

\section{Thermal analysis}

TGA was performed on a Perkin-Elmer TGA-7 thermogravimetric analyzer (Perkin-Elmer Co., Norwalk, CT, USA). The instrument was calibrated with alumel and iron standards supplied by PerkinElmer. The measurements were performed under a 
continuous flow of nitrogen or synthetic air $\left(25 \mathrm{ml} \mathrm{min}^{-1}\right)$, at $20^{\circ} \mathrm{C} \mathrm{m^{-1 }}$ to $900{ }^{\circ} \mathrm{C}$.

Differential scanning calorimeter (DSC) was performed on a Perkin-Elmer DSC-7 differential scanning calorimeter. The instrument was calibrated with indium supplied by Perkin-Elmer. The measurements were performed under a continuous flow of nitrogen $\left(25 \mathrm{ml} \mathrm{min}{ }^{-1}\right)$. The samples (1$2 \mathrm{mg}$ ) were typically equilibrated at $30^{\circ} \mathrm{C}$, ramped to $225^{\circ} \mathrm{C}\left(10^{\circ} \mathrm{C} \mathrm{min}^{-1}\right)$, and allowed to cool back to $30^{\circ} \mathrm{C}$ at $10^{\circ} \mathrm{C} \mathrm{min}^{-1}$. Three heating-cooling cycles were recorded for each sample.

\section{DRIFT spectra}

These were recorded on a Mattson Galaxy Series FTIR 300 spectrometer (Mattson Instruments, Inc., Madison, WI, USA) with a DTGS detector. Random cuttings of crystalline, optical-grade $\mathrm{KBr}$ from International Crystal Laboratories were used to prepare the sample. About $600 \mathrm{mg}$ of $\mathrm{KBr}$ was ground in a mortar with a pestle, and enough sample was ground with $\mathrm{KBr}$ to make a $0.6 \mathrm{wt} \%$ mixture. After the sample was loaded, the sample chamber was purged with nitrogen for a minimum of $10 \mathrm{~min}$ before data collection. A minimum of 250 scans were collected for each sample at a resolution of $\pm 4 \mathrm{~cm}^{-1}$.

\section{Mass spectrometry}

Mass spectra were obtained on a VG analytical model 70-250S mass spectrometer using a DCI probe for both electron-impact and $\mathrm{NH}_{3}$-ionization techniques $(\mathrm{FAB})$. The electron ionization energy was $70 \mathrm{eV}$.

Analytical mass spectra for lower-molecularweight samples (i.e. $<500$ ) were recorded on a Finnigan model 4021 quadruple GC/mass spectrometer by electron-impact ionization using the Galwin software package. Low-resolution mass spectra for higher-molecular-weight samples were obtained on a VG analytical model 70-250S mass spectrometer using a DCI probe for both electronimpact and $\mathrm{NH}_{3}$-ionization techniques. The electron ionization energy was $70 \mathrm{eV}$ for all analyses.

\section{Elemental analyses}

These were performed by the University of Michigan, Department of Chemistry, analytical services for analysis of carbon, hydrogen and nitrogen content $(\mathrm{CHN})$. At the University of Michigan, a Perkin-Elmer 2400 CHN Elemental Analyzer was operated at $1075^{\circ} \mathrm{C}$ with helium as a carrier gas. Powder specimens $(1.5 \mathrm{mg})$ were loaded into tin capsules with powdered tin (6-
$10 \mathrm{mg}$ ) as a combustion aid. Acetanilide was used as a reference standard, and was analyzed in the same manner as the samples.

\section{Synthetic methods}

\section{Octa(3-chloroammoniumpropyl) silsesquioxane (OCAPS)}

OCAPS synthesis optimization studies were conducted by varying the reaction conditions by using different acid and 3-aminopropyltrimethoxysilane concentrations, different temperatures and different reaction times. The total overall yields, no matter what the conditions, were never above $40 \%$ of theory, and most typically about $30 \%$. The following example is for a $30 \%$ yield.

OCAPS was prepared in a Schlenk flask equipped with a magnetic stirrer and nitrogen purge. First, the methanol was placed in the flask, then the 3-aminopropyltrimethoxysilane (APTS, Gelest Inc.) was introduced dropwise. The hydrochloric acid $(36.5 \mathrm{wt} \%, 12 \mathrm{M})$ was then poured quickly and the flask was closed when the fume production stopped (about 5 minutes). The reaction mixture was then stirred under nitrogen until the OAPS precipitated as a white powder (typically 510 days). The resulting OCAPS was then washed with cold, dry methanol and dried under vacuum. The compound was extremely hygroscopic and must be stored in sealed containers in a desiccator.

\section{Preparation of succinimide of OCAPS}

Succinic anhydride $(3.41 \mathrm{~g}, 34.1 \mathrm{mmol})$ and OCAPS $(0.500 \mathrm{~g}, 0.426 \mathrm{mmol})$ were placed in a 25-ml Schlenk flask equipped with a reflux condenser and a magnetic stirrer. The reaction was heated in a silicone-oil bath. Succinic anhydride melts at $\approx 130{ }^{\circ} \mathrm{C}$, and a clear yellowish solution was obtained at $\approx 180{ }^{\circ} \mathrm{C}$. After heating at this temperature for $\approx 2 \mathrm{~h}$, the reaction mixture was allowed to cool in air into a hard solid. $\mathrm{CH}_{2} \mathrm{Cl}_{2}$ $(20 \mathrm{ml})$ was added and the reaction mixture was stirred at room temperature (RT) for $2 \mathrm{~h}$, by which time the product had dissolved and a white suspension of the unreacted succinic anhydride was obtained. The succinic anhydride was filtered off, and $\mathrm{CH}_{2} \mathrm{Cl}_{2}$ was blown off under a stream of $\mathrm{N}_{2}$ to yield the crude product, succinimide, as a white solid. Trace amounts of succinic anhydride remaining in the product were removed by sublimation under vacuum at $\approx 120^{\circ} \mathrm{C}$. The crude product was recrystallized in $\mathrm{CH}_{2} \mathrm{Cl}_{2}$ /methanol to yield a white powder $(0.398 \mathrm{~g}, 61 \%$ of theoretical $)$. Selected characterization data are as follows: IR 
Table 1. NMR data for OCAPS and derivatives

\begin{tabular}{|c|c|c|c|}
\hline Cube & ${ }^{1} H\left(\delta, \mathrm{D}_{2} \mathrm{O}\right)$ & ${ }^{13} C\left(\left[\mathrm{D}_{6}\right] \mathrm{DMSO}\right)$ & $\left(\left[\mathrm{D}_{6}\right] \mathrm{DMSO}\right)$ \\
\hline OCAPS & $\begin{array}{l}0.81\left(\mathrm{t}, 2 \mathrm{H},-\mathrm{CH}_{2} \mathrm{Si}\right), 1.81(\mathrm{~m}, 2 \mathrm{H} \\
\left.-\mathrm{CH} \mathrm{H}_{2}-\right), 3.02\left(\mathrm{t}, 2 \mathrm{H},-\mathrm{CH}_{2} \mathrm{NH}_{2}\right)\end{array}$ & $\begin{array}{l}8.44\left(-\mathrm{CH}_{2} \mathrm{Si}\right), 20.63\left(-\mathrm{CH}_{2}-\right), \\
41.04,\left(-\mathrm{CH}_{2} \mathrm{NH}_{2}\right)\end{array}$ & -66.4 \\
\hline OAOCAPS & $\begin{array}{l}0.65\left(\mathrm{t}, 2 \mathrm{H},-\mathrm{CH}_{2}-\mathrm{Si}\right), 1.58(\mathrm{~m}, 2 \mathrm{H}, \\
-\mathrm{CH} 2-), 1.93\left(\mathrm{~s} .3 \mathrm{H}, \mathrm{CH}_{3} \mathrm{CO}-\right), 2.78 \\
\left(\mathrm{t}, 2 \mathrm{H},-\mathrm{CH}_{2}-\mathrm{NHCO}-\right),\end{array}$ & - & - \\
\hline HOAAPS & $\begin{array}{l}\left(\mathrm{CDCl}_{3}\right) \\
0.61\left(\mathrm{t}, 2 \mathrm{H},-\mathrm{CH}_{2}-\mathrm{Si}\right) \\
1.60\left(\mathrm{~m}, 2 \mathrm{H},-\mathrm{CH}_{2}-\right) \\
2.37\left(\mathrm{~s}, 6 \mathrm{H},-\mathrm{CO}_{-}-\mathrm{CH}_{3}\right) \\
3.58\left(\mathrm{t}, 2 \mathrm{H},-\mathrm{CH}_{2}-\mathrm{N}\right)\end{array}$ & $\begin{array}{l}\left(\mathrm{CDCl}_{3}\right) \\
\left.9.19-\mathrm{CH}_{2}-\mathrm{Si}\right) \\
22.40\left(-\mathrm{CH}_{2}-\right) \\
\left.26.37-\mathrm{CO}-\mathrm{CH}_{3}\right) \\
\left.47.23-\mathrm{CH}_{2}-\mathrm{N}\right) \\
173.06(\mathrm{C}=\mathrm{O})\end{array}$ & $\begin{array}{c}\left(\mathrm{CHCl}_{3}\right) \\
-67.5\end{array}$ \\
\hline SOCAPS & $\begin{array}{l}0.54\left(\mathrm{t}, 2 \mathrm{H},-\mathrm{CH}_{2}-\mathrm{Si}\right), 1.53(\mathrm{p}, 2 \mathrm{H}, \\
-\mathrm{CH}-, 2.67\left(\mathrm{~s}, 4 \mathrm{H},-\mathrm{CH}_{2}-\mathrm{CO}-\right), \\
3.41\left(\mathrm{t},-\mathrm{CH}_{2}-\mathrm{N}-\right) .\end{array}$ & $\begin{array}{l}\left.9.27-\mathrm{CH}_{2}-\mathrm{Si}\right), 21.26\left(-\mathrm{CH}_{2}-\right), \\
\left.28.31-\mathrm{CH}_{2}-\mathrm{CO}\right), 41.13 \\
\left(-\mathrm{CH}_{2}-\mathrm{N}\right), 177.53(-\mathrm{C}=\mathrm{O}) .\end{array}$ & -67.26 \\
\hline
\end{tabular}

$\left(\mathrm{KBr}, \mathrm{cm}^{-1}\right): 2939 \mathrm{~s}, 2890 \mathrm{~m}(v(\mathrm{C}-\mathrm{H})), 1701 \mathrm{~s}(v$ $(\mathrm{C}=\mathrm{O})), 1440 \mathrm{~m}(\delta(\mathrm{C}-\mathrm{H})), 1405 \mathrm{~s}(\nu(\mathrm{C}-\mathrm{N}))$, $1232 \mathrm{~m}(v(\mathrm{Si}-\mathrm{O})), 1141 \mathrm{~s} \quad(v(\mathrm{Si}-\mathrm{O}))$. Mass spectrum [FAB in 3-nitrobenzyl alcohol (NBA), relative percentage]: $m / z=1537(\mathrm{M}+1,1.6), 1397$ (0.3), 307 (25), 154 (NBA+1, 100), 136 (73). Elemental analysis: Found: C, 43.88; H, 5.20; N, 7.10; $\mathrm{Si}, 14.30$ (calculated from ceramic yield in air); O, 29.52. Calcd: C, 43.73; H, 5.24; N, 7.29; Si, $14.61 ;$ O, $29.13 \%$.

\section{Hexadecylacetamide cube}

To a 15-ml round-bottomed flask equipped with a magnetic stirrer and a condenser were added $0.200 \mathrm{~g}(0.171 \mathrm{mmol})$ octa-amino cube and $5 \mathrm{ml}$ $(52.0 \mathrm{mmol})$ acetic anhydride. The solution was refluxed at $140{ }^{\circ} \mathrm{C}$ for $24 \mathrm{~h}$ under nitrogen. The resulting product was dried under vacuum at $60{ }^{\circ} \mathrm{C}$ for $4 \mathrm{~h}$ and methanol was then used to wash the product and remove any remaining acetic anhydride. Methanol was evaporated under a nitrogen flow and $0.192 \mathrm{~g}$ (yield $92.5 \%$ ) of the final product was obtained. Analytical data are Table 1.

\section{RESULTS AND DISCUSSION}

A number of groups have already demonstrated that silica/amide (e.g. nylon) and imide hybrid systems produced via sol-gel techniques offer enhanced thermal stability and improved mechanical properties compared with either component alone. ${ }^{16-21}$ Our intention in the work reported here is to extend these efforts to molecular-level silica particles, e.g. cubes with direct chemical links to the polymer backbone.

The first step was to attempt to synthesize octa(aminopropyl) octasilsesquioxane (OCAPS) macromonomer by acid-catalyzed condensation of 3-aminopropyltrimethoxysilane in $\mathrm{MeOH}$. To our surprise, we were unable to prepare the octamino compound; however, we did find that OCAPS was precipitated out of solution in low yields. In an attempt to raise the yield of OCAPS, we explored the effects of variations in reaction conditions on isolated yields. Following extensive efforts, we were unable to obtain yields greater than $\approx 30 \%$ reproducibly, and these yields required reaction times of 5-10 days for the OCAPS product to precipitate out of solution. Note that our reaction times seem to be shorter than the six weeks described by Feher and Wyndham. ${ }^{15}$

OCAPS is highly hygroscopic, as might be expected for an octa-(ammonium chloride) salt. It is quite soluble in water or dimethyl sulfoxide, giving a neutral $\mathrm{pH}$ in aqueous solution. Table 1 shows the results of NMR analysis, and Table 2 shows CHN and mass spectral analyses. The ${ }^{1} \mathrm{H}$ NMR data differ slightly from those reported by Feher and co-workers, as spectra were taken in $\mathrm{D}_{2} \mathrm{O}$ rather than $\left[\mathrm{D}_{6}\right] \mathrm{DMSO}$; however, the ${ }^{13} \mathrm{C}$ and ${ }^{29} \mathrm{Si}$ data are identical. The TGA analysis (Fig. 1) of the OCAPS hydrochloride shows surprising stability, as the compound decomposes in air only at $\approx 300{ }^{\circ} \mathrm{C}$, suggesting that amide and imide derivatives might exhibit reasonable stabilities.

The next step was to attempt a simple acetylation 
Table 2. Mass spectral and chemical analyses for OCAPS and derivatives

\begin{tabular}{|c|c|c|c|c|c|}
\hline \multirow[b]{2}{*}{ Cube } & \multirow[b]{2}{*}{ Mass spectrum $m / z$ (intensity, $\%)^{\mathrm{a}}$} & \multicolumn{4}{|c|}{ Elemental analysis: Found (calcd) $(\%)$} \\
\hline & & $\mathrm{C}$ & $\mathrm{H}$ & $\mathrm{N}$ & $\mathrm{Si}$ \\
\hline OCAPS & $881\left(\mathrm{M}^{+}\right)$ & $\begin{array}{c}24.21 \\
(24.60)\end{array}$ & $\begin{array}{c}6.20 \\
(6.20)\end{array}$ & $\begin{array}{c}9.31 \\
(9.60)\end{array}$ & \\
\hline $\begin{array}{l}\text { OAOCAPS } \\
\text { HOAAPS }\end{array}$ & 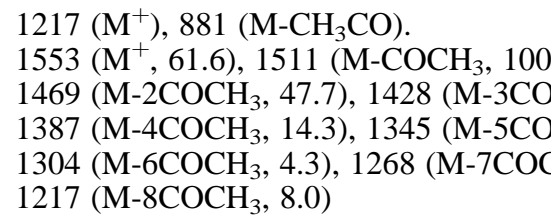 & $\begin{array}{l}25.9), \\
7.4), \\
.0),\end{array}$ & & & \\
\hline SOCAPS & $\begin{array}{l}1537(\mathrm{M}+1,1.6), 1397(0.3) \\
307(25), 154(\mathrm{NBA}+1,100) \\
136(73)\end{array}$ & $\begin{array}{c}43.88 \\
(43.73)\end{array}$ & $\begin{array}{c}5.20 \\
(5.24)\end{array}$ & $\begin{array}{c}7.10 \\
(7.29)\end{array}$ & $\begin{array}{c}14.30 \\
(14.61)^{\mathrm{b}}\end{array}$ \\
\hline
\end{tabular}

${ }^{a}$ Fast atom bombardment $(\mathrm{FAB})$ in nitrobenzyl alcohol matrix.

${ }^{\mathrm{b}}$ Calculated from ceramic yield.

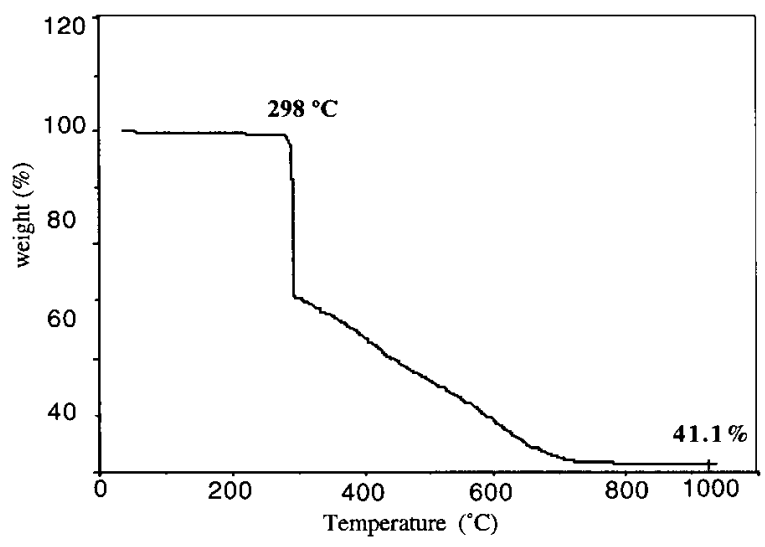

Figure 1 TGA $\left(\right.$ air $/ 10^{\circ} \mathrm{C} \mathrm{min}^{-1}$ ) of octa(3-chloroammoniumpropyl) octasilsesquioxane octahydrochloride. to determine the facility with which OCAPS undergoes amide-type reactions. To simplify our efforts, the isolated octahydrochloride was used directly for the acetylation reaction and somewhat forcing conditions were employed, refluxing acetic anhydride. Surprisingly, rather than isolating the octa-acetamide (OAOCAPS), the product recovered (>90\% yield) was the hexadecylacetamide (HOAAPS), as determined by mass spectral analysis and NMR (see Tables 1 and 2).

Efforts to produce pure OAOCAPS by reducing reaction temperatures to $60-80^{\circ} \mathrm{C}$ and using longer reaction times were not successful as the OAOCAPS appears to be more reactive towards further acetylation than OCAPS is to acetylation. Thus, the mass spectral data and NMR data found in Tables 1 and 2 were gleaned from spectra of mixtures of the<smiles>NCCC[Si]12O[Si]3(CCCN)O[Si]4(CCCN)O[Si](CCCN)(O1)O[Si]1(CCCN)O[Si](CCCN)(O2)O[Si](CCCN)(O3)O[Si](CCCN)(O4)O1</smiles>

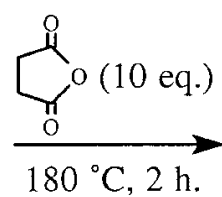

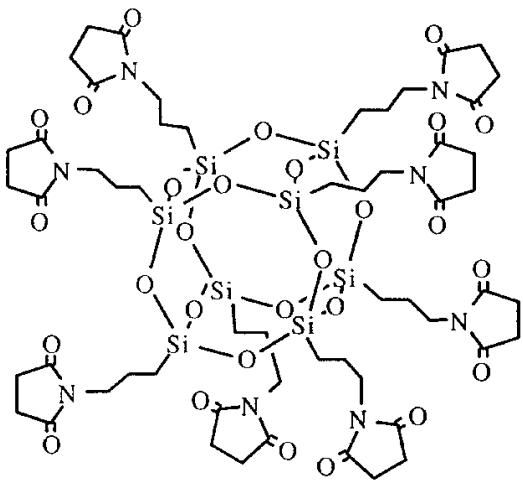

Scheme 7 


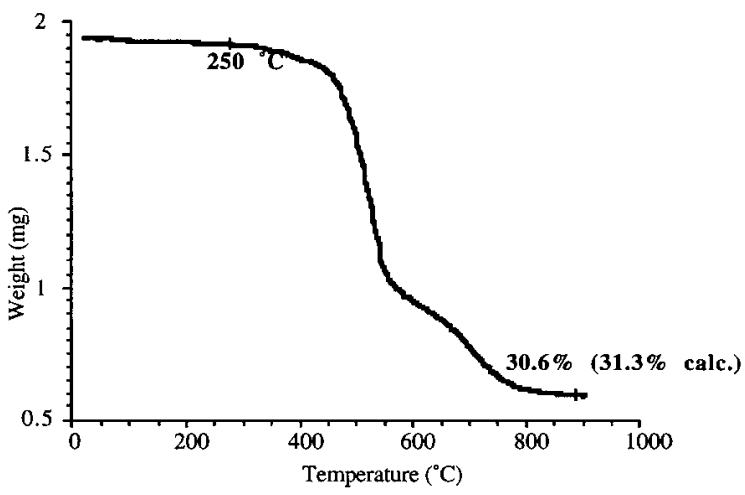

Figure 2 TGA $\left(\right.$ air $\left./ 10^{\circ} \mathrm{C} \min ^{-1}\right)$ of octa(3-succinimidopropyl) octasilsesquioxane.

two products with or without starting material, where the OAOCAPS never amounted to more than $30-40 \%$ of the product.

Our inability to isolate the OAOCAPS made it impossible to study the potential properties of this material as a model for polyamides. However, the peracetylation suggested that imides might be easily accessible. Therefore, we explored this possibility by replacing acetic anhydride with succinic anhydride as reactant, as shown in Scheme 7. Scheme 7 goes to completion in a short time $(2 \mathrm{~h})$ and provides nearly quantitative yields of the octasuccinimide (SOCAPS). No evidence for any intermediates or incomplete reaction is seen in the NMR and mass spectral analyses.

The TGA analyses in air and nitrogen are quite informative. First the air TGA (Fig. 2) shows a final ceramic yield of $30.6 \mathrm{wt} \%$, which is very close to the calculated ceramic yield of $31.3 \mathrm{wt} \%$, indicating a high-purity product. Second, the absence of

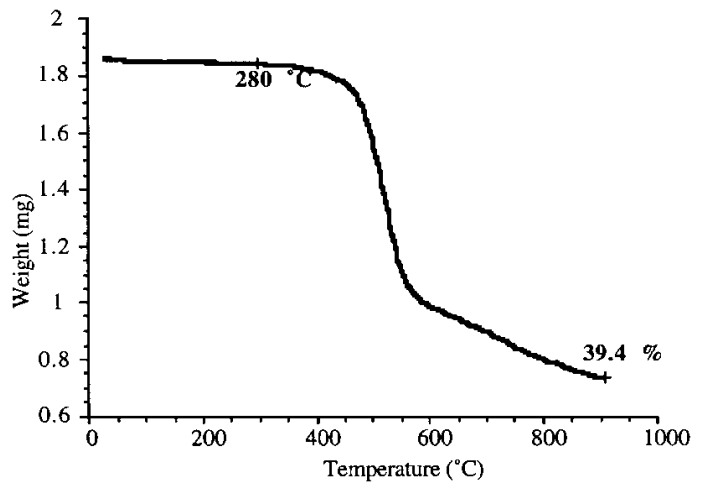

Figure 3 TGA (nitrogen $/ 10^{\circ} \mathrm{C} \min ^{-1}$ ) of octa(3-succinimidopropyl) octasilsesquioxane.

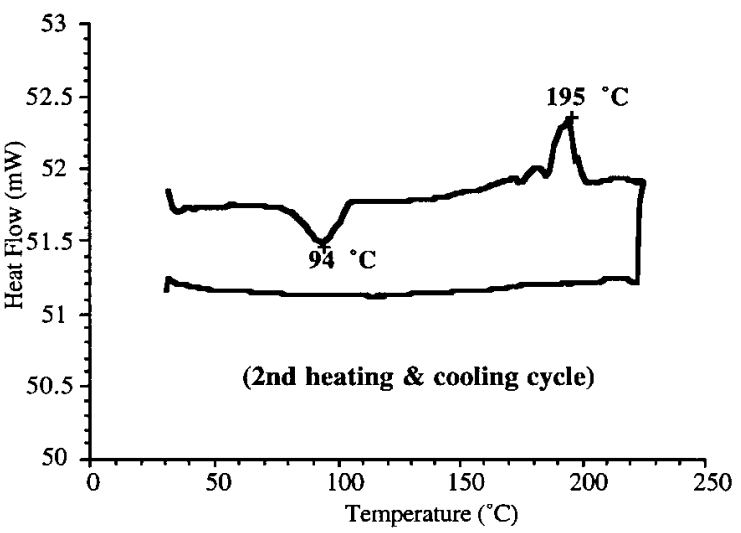

Figure 4 DSC (nitrogen $/ 10^{\circ} \mathrm{C} \min ^{-1}$ ) of octa(3-succinimidopropyl) octasilsesquioxane.

any major mass losses before $\approx 400{ }^{\circ} \mathrm{C}$ in air is very promising in that it suggests high stability for any polyimides or copolyimides that might be prepared using cubic silsesquioxanes. This is very important because the high silica content plus the hightemperature stability suggest that these materials will be very useful for applications requiring flame resistance and high strength.

The SOCAPS TGA in nitrogen (Fig. 3) shows stability to temperatures of almost $500^{\circ} \mathrm{C}$. Taken together, these data suggest that polyimides made with aromatic anhydrides might be even more temperature-resistant.

The DSC results (second heat-cool cycle) shown in Fig. 4 provide still more interesting results. During the heating stage, an exotherm centered at $\approx 94^{\circ} \mathrm{C}$ is followed by a small endotherm that begins at $\approx 180^{\circ} \mathrm{C}$ and is followed by a larger endotherm at $190{ }^{\circ} \mathrm{C}$. A sample placed on the hot stage of a polarizing microscope exhibits isotropic behavior below $90^{\circ} \mathrm{C}$ (second heat-cool cycle) and then it exhibits birefringence on heating above $180{ }^{\circ} \mathrm{C}$. The birefringence remains until the material is heated above $190{ }^{\circ} \mathrm{C}$. At this point it flows freely on the hot stage. We interpret these results to suggest that on heating a crystallization event occurs first (exotherm). Heating to $\approx 180{ }^{\circ} \mathrm{C}$ leads to formation of what we tentatively assigned as a liquid-crystalline (LC) phase. On continued heating, the LC phase becomes isotropic at $\approx 190{ }^{\circ} \mathrm{C}$ (endotherm). The cooling curve shows a slight upturn that a referee has suggested might be due to a vitrification process. The fact that no rigid aromatic groups are attached to the cube makes the observation of LC behavior quite unique, if it is indeed an LC phase. We plan to report in detail on 
this behavior in a future publication (C. Zhang, L. Gonzalez, D. Martin and R.M. Laine, unpublished results).

Acknowledgements We thank the National Institute of Dental Research for support of this work through NIDR grant no. DE09839-03 and the Federal Aviation Administration for support of this work through Contract no. 95-G-026. We thank Ms Lisa Viculis for helping reproduce some of the original results and Ms L. Gonzalez for conducting the preliminary hotstage studies. We thank a referee for guiding our interpretation of the hot-stage and DSC results.

\section{REFERENCES}

1. M. G. Voronrov and V. I. Lavrent'yev, Top. Curr. Chem. 102, 199 (1982).

2. (a) J. D. Lichtenhan, Comm. Inorg. Chem. 17, 115 (1995) (b) J. D. Lichtenhan, H. Q. Vu, J. A. Carter, J. W. Gilman and F. J. Feher, Macromolecules 26, 2141 (1993).

3. Y. Chujo, Curr. Opin. Solid State Mater. Chem. 806 (1996).

4. J. E. Marks, Polym. Eng. Sci. 36, 2905 (1996).

5. R. A. Vaia, K. D. Jandt, E. J. Kramer and E. P. Giannelis, Chem. Mater. 8, 2628 (1996).

6. A. Sellinger, R. M. Laine, V. Chu and C. Viney, J. Polym. Sci. Part A, Polym. Chem. 32, 3069 (1994).
7. A. Sellinger and R. M. Laine, Macromolecules 29, 2327 (1996).

8. A. Sellinger and R. M. Laine, Chem. Mater. 8, 1592 (1996).

9. C. Zhang and R. M. Laine, J. Organometal. Chem. 521, 199 (1996).

10. R. Weidner, N. Zeller, B. Deubzer and V. Frey, US Patent. 5047492, (1991).

11. T. Cassagneau, D. J. Jones and J. Rozières, J. Phys. Chem. 97, 8678 (1993).

12. T. Cassagneau, D. J. Jones and J. Rozières, Chem. Mater. 8 , 1758 (1996).

13. A. Szabo, D. Bournis, M. A. Karakassides and D. Petridis, Chem. Mater. 10, 630 (1998).

14. M.-C. Gravel and R. M. Laine, Am. Chem. Soc. Div. Polym. Cl. Polym. Prepr. 38, 155 (1997).

15. F. J. Feher and K. D. Wyndham, J. Chem. Soc. Chem. Commun. 323 (1998).

16. L. L. Beecroft, N. A. Johnen and C. K. Ober, Polym. Adv. Technol. 8, 289 (1997).

17. S. T. Hobson and K. J. Shea, Chem. Mater. 9, 616 (1997).

18. R. A. Zoppi, C. R. de Castro, I. V. P. Yoshida and S. P. Nunes, Polymer 38, 5705 (1997).

19. P. Sysel, R. Pulec and M. Maryska, Polym. J. 29, 607 (1997).

20. Z. Ahmad, M. I. Sarwar, S. Wang and J. E. Mark, Polymer 38, 4523 (1997).

21. C. V. Avadhani, Appl. Organometal. Chem. 11, 153 (1997). 